\title{
Use of Cucurbita pepo Oil to Fight against the UV Action on the Skin
}

\section{Aristide H. W. Nakavoua ${ }^{1 *}$, Guy Crépin Enoua², Stéphanie Manhan-Iniangas ${ }^{3}$, Pierre Chalard ${ }^{4}$, Gilles Figuérédo 5}

${ }^{1}$ Laboratory of Natural Substances Chemistry (IRSEN), Brazzaville, Republic of Congo

${ }^{2}$ Analytical Chemistry and Bioactive Substances Team, Faculty of Science and Technology, Marien Ngouabi University, Brazzaville, Republic of Congo

${ }^{3}$ Laboratory for the Valorisation of Agri-Resources, National Polytechnic High School (ENSP), Marien Ngouabi University, Brazzaville, Republic of Congo ${ }^{4}$ Institute of Chemistry of Clermont-Ferrand (ICCF), Clermont-Ferrand, France

${ }^{5}$ LEXVA Analytical, Clermont Ferrand, France

Email: *a.nakavoua@lycee-saintexbrazza.org

How to cite this paper: Nakavoua, A.H.W., Enoua, G.C., Manhan-Iniangas, S., Chalard, P. and Figuérédo, G. (2021) Use of Cucurbita pepo Oil to Fight against the UV Action on the Skin. Green and Sustainable Chemistry, 11, 49-58.

https://doi.org/10.4236/gsc.2021.112005

Received: January 15, 2021

Accepted: March 8, 2021

Published: March 11, 2021

Copyright (c) 2021 by author(s) and Scientific Research Publishing Inc. This work is licensed under the Creative Commons Attribution International License (CC BY 4.0).

http://creativecommons.org/licenses/by/4.0/

\begin{abstract}
Skin aging is a process most often attributed to UV [1] and also to the use of creams and other cosmetic products low in antioxidant compounds [2]. Photochemically stable pepo Cucurbita oil can be used as an exogenous cosmetic supplement due to its high antioxidant content. Incorporated in an agar, media containing a synthetic melanin solution with added pumpkin oil are subjected to UV light, the aging thus modeled is followed by the measurement of photoresistance values correlated with chemical and spectrophotometric analyses. This study confirms that pumpkin oil is highly effective in protecting the skin, especially the most sensitive skins such as babies' skin [3] by reinforcing the action of melanin and also that of albinos without melanin. Indeed its SPF (Significant Sun Protection Factor) index estimated during this work is very consistent, i.e. more than $22 \%$ of UVB $(280-315 \mathrm{~nm})$ radiations are suppressed.
\end{abstract}

\section{Keywords}

Aging, Vegetable Oil, Cucurbita pepo, Photoresistance, Melanin, UV

\section{Introduction}

The Congo, our country, is located in the zone with a high UV exposure index [4]. Although diseases related to UV threats are hardly encountered in this 
country [5], nevertheless, there is still the need to research ways to mitigate the effects of UV on our skins by using local products at lower cost.

Thanks to its great botanical diversity favored by the humid tropical climate, the Congo is a large reserve of oil-producing plants, some of which contain an oil with a high potential in simple and complex antioxidant compounds that increase its oxidation stability, such as Cucurbita pepo [6]. These oils can be used as an exogenous complement in the popularization of a number of cosmetic products such as sun creams [2].

Aging is all natural and artificial processes that tend to alter the structure of a building or an organ such as the skin [7]. These processes result in a certain number of chemical and biochemical reactions which, in the case of the skin, are most often triggered by UV rays [8]. The inevitable exposure to UV rays is the cause of damage to our skin; however, we must take into account the type of skin and the quantity of melanin that it can synthesize to efficiently face the UV ray threat [9].

The agar containing solutions with certain characteristics undergoes the action of UV rays and the ensuing aging monitored thanks to a photoresistance connected to an ohmmeter. The variation of the resistance coupled with physico-chemical methods made it possible to estimate the impact of the aging thus simulated and also the SPF index of this oil.

\section{Materials and Methods}

\subsection{Oil Extraction Process}

The dry seeds were bought on the Total market place in Brazzaville. They were crushed using an electric grinder equipped with a rotor calibrated at $2500 \mathrm{rpm}$. The grind (powder) also called cake obtained was pressed to extract the oil, the extraction rate was determined according to the Afnor standard. The oil obtained was filtered and then stored in dark glass bottles and placed away from the light.

\subsection{Fatty Acid Composition}

Fatty acid esters are obtained after direct methylation: 2 drops of oil in $1 \mathrm{~mL}$ hexane in the presence of $0.4 \mathrm{~mL} 1 \mathrm{~N}$ soda (in methanol) heated for one minute. Then $0.4 \mathrm{~mL} 1 \mathrm{~N}$ hydrochloric acid in methanol is added followed by $1 \mathrm{~mL}$ hexane [10].

The chemical composition is determined by GC/FID using an AGILENT 5890 instrument equipped with a $100 \mathrm{~m}$-long Supelco FAMES column with an inner diameter of $0.25 \mathrm{~mm}$ and a thickness of $0.25 \mu \mathrm{m}$. This apparatus delivers hydrogen $\left(\mathrm{H}_{2}\right)$ as carrier gas at $0.7 \mathrm{~mL} \cdot \mathrm{min}^{-1}$. It is equipped with an oven whose temperature rises to $140^{\circ} \mathrm{C}$ and then the temperature continues to rise for 5 minutes at a rate of $4^{\circ} \mathrm{C} \cdot \mathrm{min}^{-1}$ up to $240^{\circ} \mathrm{C}$. The temperature of the injector is at $280^{\circ} \mathrm{C}$ with a split of $1 / 30$ and injecting a volume of $1 \mu \mathrm{L}$, that of the detector is at $300^{\circ} \mathrm{C}$ at a rate of $40 \mathrm{~mL} \cdot \mathrm{min}^{-1}$ for hydrogen $\left(\mathrm{H}_{2}\right)$ and $450 \mathrm{~mL} \cdot \mathrm{min}^{-1}$ for air fi- 
nally a Make up of $45 \mathrm{~mL} \cdot \mathrm{min}^{-1}$ for nitrogen $\left(\mathrm{N}_{2}\right)$.

\subsection{Physico-Chemical Analyses}

The main physico-chemical indices were determined by referring to international and French standards [11]. We have thus realized the acid index IA (NF EN ISO 660), the saponification index IS (NF EN ISO 3657), the peroxide index IP (NF T 60 - 220). The density determination is carried out using a pycnometer according to standardized methods (NF ISO 6883).

\subsection{Melanin and Sampling Enzymatic Synthesis}

Melanin is a molecule that is fairly easy to synthesize, in fact, the synthesis of melanin does not directly give the molecule but a solution in which we find the melanin molecule. Melanin synthesis is mainly controlled by an enzyme, tyrosinase, which is involved in the transformation of tyrosine (Merck type) into melanin. The synthesis is carried out according to the French standard (Table 1).

For the samples (Table 2), $0.15 \mathrm{~g}$ Agar in $10 \mathrm{~mL}$ distilled water was prepared. However, before pouring into the petri dishes, $5 \mathrm{~mL}$ of melanin solution was added to form sample 2. After cooling, the sliced agars were coated on both sides with pumpkin oil (samples 1 and 3).

Table 1. Synthesis operating mode.

Synthesis process

\begin{tabular}{|c|c|}
\hline Step 1 & $\begin{array}{l}\text { Preparation of button mushroom extract: } \\
\text { - Grind } 50 \mathrm{~g} \text { of button mushroom } \\
\text { - Mix with } 100 \mathrm{~mL} \text { of distilled water } \\
\text { - Filter all } \\
\text { - Keep in the refrigerator }\end{array}$ \\
\hline Step 2 & $\begin{array}{l}\text { Preparation of the tyrosine solution: } \\
\text { - Measure } 0.1 \mathrm{~g} \text { of tyrosine powder } \\
\text { - Mix with } 100 \mathrm{~mL} \text { of distilled water } \\
\text { - Heat while stirring until the powder dissolves } \\
\text { - Keep in the refrigerator }\end{array}$ \\
\hline Step 3 & $\begin{array}{l}\text { Both reagents mixture: } \\
\text { - In test tubes, mix } 4 \mathrm{~mL} \text { potato extract and } 2 \mathrm{~mL} \text { tyrosine } \\
\text { - Immerse the tubes in a calibrated water bath at } 37^{\circ} \mathrm{C} \\
\text { - Wait an hour and then observe the color }\end{array}$ \\
\hline
\end{tabular}

Table 2. Summary of different samples.

\begin{tabular}{cc}
\hline & Samples \\
\hline Samp 1 & Agar + oil \\
Samp 2 & Agar + melanin \\
Samp 3 & Agar + melanin + oil \\
\hline
\end{tabular}




\subsection{Aging}

A UV stress, depending on time, allowed to model the aging of each agar sample by determining the resistance given by the photoresistance. A photoresistor is an electronic component whose electrical resistance $R$, expressed in ohm $(k \Omega)$, varies according to the amount of received light (radiation). Twelve acquisitions spaced 5 minutes apart were carried out in each case.

The sample is attached to the photoresistance cell itself connected to an ohmmeter; the whole is placed under a UV lamp of brand (UV lamp 254 and $365 \mathrm{~nm}$ ) and capacity $6 \mathrm{~W}$.

After the acquisitions the agar is immersed in $10 \mathrm{~mL}$ of Merck type hexane to recover the soaked oil in order to perform the methylation.

\subsection{Spectroscopic Method}

Spectroscopy is an excellent means of comparison, the spectra collected in the visible range of solutions (tyrosine and melanin) are thus used to effectively establish the transition from tyrosine to melanin. The data are processed using the scientific workshop software delivered with the spectrophotometer.

Visible spectroscopy: the sample is diluted so that the absorbance between 380 and $780 \mathrm{~nm}$ is between 0.8 and 1 . The solution containing the sample is placed in a plastic cell with a $1 \mathrm{~cm}$ optical path. It is introduced into the scanning spectrophotometer and then the spectrum is recorded with a resolution of 32 acquisitions [11].

\subsection{Estimation of Oil SPF}

Since the photoresistance reacts according to the amount of UV light reaching its surface, it is possible to roughly estimate the protection index (PI) of Cucurbita pepo oil spread or mixed with the sample [12]. Indeed, the measured resistance is related to the transmittance and therefore to the absorbance of the sample, the difference of the values recorded for the different samples constitutes a sufficient database to estimate the SPF of this oil by the following calculation.

$$
\mathrm{SPF}=\left(1-\frac{\mathrm{R}_{\text {samp3 }}}{\mathrm{R}_{\text {samp2 }}}\right) \times 100
$$

\section{Results and Discussion}

\subsection{Physico-Chemical Indices Analysis}

Pumpkin oil is a fatty substance with a high percentage of unsaturated fatty acids, more than $80 \%$ unsaturated. It is therefore a pale yellow liquid oil at room temperature, very rich in phenolic compounds that help it resist aging [13].

Table 3 shows an average peroxide value close to 0.7, which indicates that the pumpkin oil used in this work is of excellent quality and freshness. Indeed, the peroxide value is a basic indicator for the characterization of the state of degradation of a fat [14]. The higher this index, the more the fat is degraded. 
Table 3. Physico-chemical indices results.

\begin{tabular}{ccccc}
\hline Parameters/Tests & Test 1 & Test 2 & Test 3 & mean \\
\hline Acid index & 10.659 & 9.537 & 8.976 & $\mathbf{9 . 7 2 4}$ \\
Saponification index & 182.32 & 190.74 & 185.13 & $\mathbf{1 8 6 . 0 6}$ \\
Peroxyde index & 0.7 & 0.6 & 0.8 & $\mathbf{0 . 6 7 5}$ \\
Esther index & 171.661 & 181.203 & 176.154 & $\mathbf{1 7 6 . 3 3 9}$ \\
Density & 1.407 & 1.398 & 1.402 & $\mathbf{1 . 4 0 3}$ \\
\hline
\end{tabular}

The average acidity of our oil is close to 10, a fairly high value compared to that given by [13] for samples of oil qualified as "young" (average value close to 7.5).

Such a disagreement suggests that in the press the extraction of pumpkin oil is done at the same time as endogenous enzymes present in the ripe seeds. These enzymes therefore continue their action within the matrix of the extracted oil, thus promoting the hydrolysis of TAGs, hence the increase in the number of free FAs in the oil. Indeed, it should be recalled that the author had worked on hot extracted oils (Soxhlet), this method has indeed the disadvantage of destroying the endogenous enzymes since the temperatures and heating time are very high.

The average value of the saponification index (Is) close to 175 is also far from those given by [13], while it proves the existence in the oil matrix of carbon chains of high average molecular weight. Indeed, the saponification index is an important indicator that makes it possible to estimate the length of carbon chains. This result is certainly related to the extraction process of pumpkin oil. Indeed, in the absence of heating, the molecular rearrangements pinpointed by the authors cited below do not occur. This result is consistent with the low presence of peroxides in this oil whose average value is around 0.7 gram equivalent per kilogram of oil. But also with the very high density measured confirms the presence of high molecular weight carbon chains [15].

It is known that the variation of physical and chemical indices is a basic criterion that is linked to the degradation of a fatty substance. It should be remembered that these characteristics do not allow us to follow the aging of our oil. However, it is important to underline them to show the state of used oil.

Like the saponification index, the ester index allows us here to estimate the oxidation state of pumpkin oil.

\subsection{Visible Spectroscopy.}

The visible spectrum (Figure 1) profiles the behavior of tyrosine and synthesized melanin extracts. Indeed, during the synthesis of melanin, a complex matrix is obtained consisting of a number of compounds including melanin. The synthesis is therefore not specifically focused on obtaining a pure product but a rather complex mixture. 


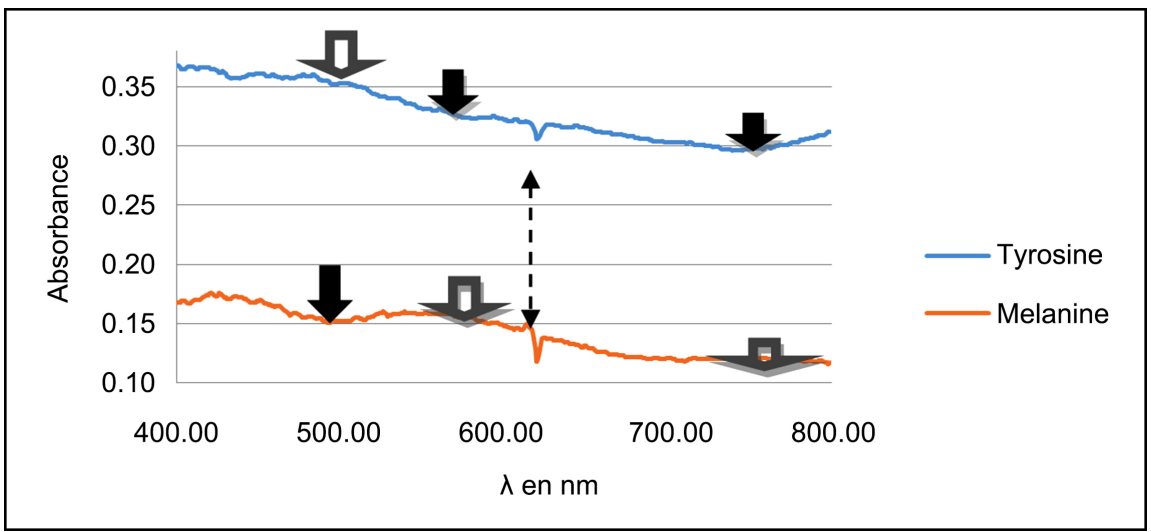

Figure 1. Profile of tyrosine and synthesized melanin; obtained by visible spectroscopy.

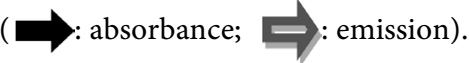

The comparison of the profiles obtained by spectroscopy of one of the used reagents and the obtained product is thus an irrefutable proof of the effectiveness of a chemical transformation.

Thus, we notice two profiles quite close but with significant differences (Figure 1). Indeed, when an absorption is observed (black arrow in figure) on one of the spectra, an emission (white arrow in figure) is visible on the other at the same wavelength. These differences indeed indicate that tyrosine reacted well and that melanin is well obtained.

A shoulder near $620 \mathrm{~nm}$ on the tyrosine spectrum is observed (Figure 1), which is much accentuated at the same wavelength on the melanin spectrum (double arrow in figure).

\subsection{UV Stress Analysis}

The evolution of resistance in $\mathrm{k} \Omega$ given by Figure 2 reveals that melanin is perfectly resistant to UV stress. Indeed, the comparison of the evolution of the different samples subjected to stress clearly shows that the values collected for Echa.2 are higher than those of Echa.1 which proves the high resistance of melanin to UV compared to pumpkin oil. This result is logical if the electromagnetic radiation used is of a luminous nature, as the oil is yellowish and therefore much more capable of diffusing light radiation than the melanin solution, which is dark and therefore more likely to absorb it. In view of these results, it is clear that the UV rays act like light on both substances. We notice over the first $5 \mathrm{mi}$ nutes that the two substances diverge in their behavior to UV. It should be noted that the amount of UV radiation transmitted by the pumpkin oil does not vary over the rest of the duration of the stress, there is a platform. This behavior proves that pumpkin oil can be used to help stabilize the impact of UV radiation on a substance and confirms the good UV stability of the oil [2].

The behavior of melanin also shows that there are stages; a first (10 to $35 \mathrm{mi}$ nutes) and a second shorter one (40 to 50 minutes); it is as if the capacity of melanin to absorb and diffuse UV increases during stress. 


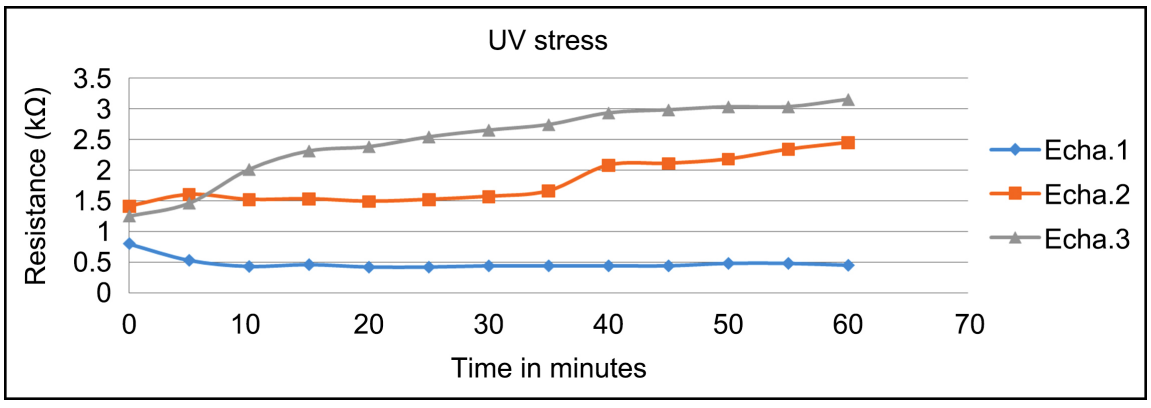

Figure 2. Monitoring the effectiveness of the contribution of Cucurbita pepo oil in UV resistance.

The analysis of the evolution in Samp.3 shows that the performance of melanin is not only to increase but above all to optimize.

In fact, everything happens as if a high quality protective layer had been placed on top of the melanin in order to reinforce its resistance to UV rays. This result is very important in the valorization of Cucurbita pepo oil.

\subsection{FA Composition Analysis}

The composition of pumpkin seed oil summarized in Table 4 confirms that this oil, although rich in unsaturated fatty acids, is still a high C18:2 oil.

There are wide variations in the chemical composition of the oil, including a decrease in the content of saturated fatty acids and the appearance of a saturated fatty acid with a long carbon chain.

During the various UV stresses, it is clear that the C18:2 content increases. This trend can be explained by the fact that the UV action triggers radical reactions whose impact is much more pronounced on saturated compounds [16]. In addition, this increase shows that pumpkin oil, thanks to its antioxidant compounds, resists degradation, in fact, the presence of antioxidant compounds creates a reactive competition in the reactivity of different fatty acids, which rather promotes the protection of C18:2 [17] while being naturally unfavorable to C18:3, in fact their content decreases during UV stress.

The appearance of C20:0 can be analyzed as being the result of molecular rearrangements initiated by the action of UV light in the oil matrix. This results in a more cross-linked oil matrix that behaves like a biodegradable and protective polymer film [13].

\subsection{Pumpkin Oil SPF Estimation}

The following Table 5 shows the estimated SPF of Cucurbita pepo seed oil, whose chemical composition is very close to that of grape seed oil and raspberry seed oil, the latter two oils having the highest SPF.

We notice that the protection index of this oil alone is already in the norm, in fact, the sunscreen generated by the contribution of pumpkin seed oil blocks $22 \%$ of the hottest UVB and this is even more encouraging given that the $\mathrm{Cu}$ curbita pepo abundant in tropical areas where the skin is mostly well melanized. 
Table 4. FA chemical composition.

\begin{tabular}{ccccccc}
\hline \multirow{2}{*}{ \% FA } & \multicolumn{2}{c}{ Test 1 } & \multicolumn{2}{c}{ Test 2 } & \multicolumn{2}{c}{ Test 3 } \\
\cline { 2 - 7 } & Before & After & Before & After & Before & After \\
\hline C16:0 & 15.76 & 15.21 & 16.23 & 14.30 & 11.29 & 11.05 \\
C18:0 & 12.92 & 12.41 & 13.19 & 12.32 & 12.59 & 11.17 \\
C18:1 & 12.71 & 14.73 & 14.90 & 12.60 & 14.11 & 13.67 \\
C18:2 & 56.83 & 56.91 & 54.83 & 59.49 & 60.32 & 62.26 \\
C18:3 & 0.30 & 0.22 & 0.45 & 0.25 & 0.39 & 0.28 \\
C20:0 & - & 0.32 & - & 0.34 & - & 0.47 \\
\hline
\end{tabular}

Table 5. SPF calculation.

\begin{tabular}{ccc}
\hline & Resistance mean & SPF \\
\hline Samp.3 & $1.5 \Omega$ & \\
Samp.2 & $2.49 \Omega$ & $22 \%$ \\
Ratio & 0.78 & \\
\hline
\end{tabular}

This estimate is reliable because the resistance value increases when the UV no longer reaches the photoresistance cell [18] and is therefore better reflected or absorbed. However, Figure 2 shows that the transmittance is rather high during the minutes following the impregnation of the Cucurbita pepo oil, this result proves that the sunscreen (protective film) caused by the oil [19] is deployed once the oil has undergone the effects of UV, the antioxidants abundant in this oil organize a kind of reaction promoting the deployment of the protective film.

\section{Conclusion}

Pumpkin oil (Cucurbita pepo), an oil with multiple uses, finds through this work a new form of recovery thanks to its great capacity to resist photochemical effects. The simulation of aging carried out has enabled us to follow the evolution of melanin behavior under UV stress; the results confirm that melanin provides perfect protection against photochemical effects of UV [7] and this protection can be optimized by adding oil [12] from an unconventional oilseed: Cucurbita pepo. Indeed, many antioxidant compounds present in the unsaponifiable matter of this oil allow fighting considerably against photochemical stress due to UV [2]. Moreover, the estimate of its protection index is in the standard and shows that this oil has a strong protective power against UV. Spectroscopy was used here to compare the spectra in the visible range of the two solutions, the tyrosine solution that is the precursor of melanin synthesis from a diluted solution of Paris fungus tyrosinase extracts and the melanin solution. The obtained results have the merit of showing that our device works and that there is a logical cohe- 
rence between the absorbed radiation, the properties of the photoresistance on the one hand and the UV absorbance by the pumpkin seed oil (Cucurbita pepo) on the other hand; one more step in the valorization of pumpkin seed oil $(\mathrm{Cu}$ curbita pepo).

\section{Conflicts of Interest}

The authors declare no conflicts of interest regarding the publication of this paper.

\section{References}

[1] Campiche, R., Curpen, S.J., Lutchmanen-Kolanthan, V., Gougeon, S., Cherel, M., Laurent, G., Schuetz, R., et al. (2020) Pigmentation Effects of Blue Light Irradiation on Skin and How to Protect against Them. International Journal of Cosmetic Science, 42, 399-406. https://doi.org/10.1111/ics.12637

[2] Krutmann, J., Morita, A. and Chung, J.H. (2012) Sun Exposure: What Molecular Photodermatology Tells Us about Its Good and Bad Sides. Journal of Investigative Dermatology, 132, 976-984. https://doi.org/10.1038/jid.2011.394

[3] Lakhlifi, D. (2019) Les Ultraviolets et Ses Effets Cellulaires Chez L'Enfant. Doctoral Dissertation.

[4] Sklar, L.R., Almutawa, F., Lim, H.W. and Hamzavi, I. (2013) Effects of Ultraviolet Radiation, Visible Light, and Infrared Radiation on Erythema and Pigmentation: A Review. Photochemical \& Photobiological Sciences, 12, 54-64. https://doi.org/10.1039/C2PP25152C

[5] World Health Organization and International Commission on Non-Ionizing Radiation Protection (2002) Indice universel de rayonnement UV solaire: Guide pratique (No. WHO/SDE/OEH/02.2). Organisation mondiale de la Sante, Geneve.

[6] Nakavoua, A.H.W., Mampouya, D., Loumouamou, A.N., Silou, T., Chalard, P., Guyot, G., Chalchat, J.C., et al. (2011) Compared Ageing of Oil from Cucurbita pepo in Two Different Storage Conditions. Advance Journal of Food Science and Technology, 3, 132-143.

[7] Beylot, C. (2009) Vieillissement cutané: Aspects cliniques, histologiques et physiopathologiques. Annales de Dermatologie et de Vénéréologie, 136, S263-S269. https://doi.org/10.1016/S0151-9638(09)72530-X

[8] Dupont, E., Gomez, J. and Bilodeau, D. (2013) Beyond UV Radiation: A Skin under Challenge. International Journal of Cosmetic Science, 35, 224-232. https://doi.org/10.1111/ics.12036

[9] Greinert, R., Breitbart, E.W., Mohr, P. and Volkmer, B. (2014) Health Initiatives for the Prevention of Skin Cancer. In: Sunlight, Vitamin D and Skin Cancer, Springer, New York, 485-499. https://doi.org/10.1007/978-1-4939-0437-2 27

[10] AOAC (2019) Official Methods of Analysis of the Association of Official Analytical Chemists: Official Methods of Analysis of AOAC International. 21st Edition, AOAC, Washington DC.

[11] Corps Gras, Graines oléagineux et produits derivés Tome 1 AFNOR 2000; Edition prolia.

[12] Pescia, A.C., Astolfi, P., Puglia, C., Bonina, F., Perrotta, R., Herzog, B. and Damiani, E. (2012) On the Assessment of Photostability of Sunscreens Exposed to UVA Irradiation: From Glass Plates to Pig/Human Skin, Which Is Best? International 
Journal of Pharmaceutics, 427, 217-223.

https://doi.org/10.1016/j.ijpharm.2012.02.001

[13] Nakavoua, A.H.W., Mampouya, D., Loumouamou, A.N., Silou, T., Chalard, P., Verney, V., Figueredo, G., et al. (2013) Accelerated Ageing Effects on Cucurbita pepo Seed Oil. Advance Journal of Food Science and Technology, 6, 806-821. https://doi.org/10.19026/ajfst.5.3144

[14] Codex Alimentarius Commission (2019) Codex Alimentarius Commission and Report of the 30th Session of the Codex Committee on Nutrition and Foods for Special Dietary Uses.

[15] Noumi, G.B., Njouokam, Y.M., Njiné, C.B., Ngameni, E. and Kapseu, C. (2011) Effets du séchage sur le rendement et la qualité de l'huile extraite de la pulpe de safou. Tropicultura, 29, 138.

[16] Irshad, A., Delor-Jestin, F., Chalard, P. and Verney, V. (2015) Physico-Chemical Durability Criteria of Oils and Linked Bio-Based Polymers. OCL, 22, D107. https://doi.org/10.1051/ocl/2014048

[17] Roman, O. (2012) Mesure et prédiction de la réactivité des lipides au cours du chauffage d'huiles végétales à haute température. Doctoral Dissertation.

[18] Malyutina-Bronskaya, V.V., Zalesskii, V.B., Konoiko, A.I. and Malyshev, V.S. (2015) Silicon Solar Cells with Vertical pn Junctions for Hybrid Solar Cells. 2015 16th IEEE International Conference of Young Specialists on Micro/ Nanotechnologies and Electron Devices, Erlagol, 29 June-3 July 2015, 87-89.

https://doi.org/10.1109/EDM.2015.7184495

[19] Hojerová, J., Medovcíková, A. and Mikula, M. (2011) Photoprotective Efficacy and Photostability of Fifteen Sunscreen Products Having the Same Label SPF Subjected to Natural Sunlight. International Journal of Pharmaceutics, 408, 27-38. https://doi.org/10.1016/j.ijpharm.2011.01.040 